\title{
DIFFUSION OF ELECTRONIC COMMERCE IN SMALL AND MEDIUM ENTERPRISES
}

\author{
Robyn Lawson \\ School of Computing and Information Technology \\ University of Westem Sydney \\ Campbelltown, Australia \\ email: R.Lawson@uws.edu.au \\ Dr Carole Alcock \\ School of Information Technology and Computer Science \\ University of Wollongong \\ Wollongong, Australia \\ email: Carole Alcock@uow.edu.au \\ Professor Joan Cooper \\ Dean, Faculty of Informatics \\ University of Wollongong \\ Wollongong, Australia \\ email: Joan Cooper@uow.edu.au
}

\begin{abstract}
Using the Internet for electronic business has become an area of action for the Australian Govemment. This paper presents research results from two regional areas which indicate that while most manufacturing SMEs use email, very few are involved in elecronic commerce activities. Major barriers are concern about security and privacy of transactions, cost of consultants, and lack of IT expertise of staff. Employing people with appropriate knowledge has been added to current training methods such as on-the-job training. Results from the two regional areas are found to be consistent. Comparisons between small and medium organisations highlight some differences.
\end{abstract}

Keywords electronic commerce, electronic business, manufacturing, SMEs.

\section{INTRODUCTION}

The evolution of the Internet as a commercial tool for conducting business has led to an increase in the use of online services. E-commerce has emerged as a whole of business strategy offering a range of services and opportunities for electronic trading in the global marketplace. The use of information and communication technologies enables organisations to improve business processes and communication within the organisation and with trading partners.

The way business is conducted is experiencing change worldwide, and is clearly evident in Australia. Globally, e-business revenue is estimated to reach US $\$ 6.8$ trillion by 2004 representing $8.6 \%$ of the world-wide sale of goods and services (Hobley 2001). The use of IT, the Internet and e-business activities have generated considerable interest. Consequently, the Australian government asserts that e-commerce will provide many new opportunities to expand exports and create thousands of new jobs, and so enhance economic growth (DFAT 1997). Certainly, the media have portrayed the image that business will predominantly be conducted on-line in the future, and organisations that do not embrace the new technologies will be left behind. As pointed out by Roseberg (1976 cited in Forester 1985:605) diffusion of new technology can take decades, and involves more than simply reproducing and distributing the technology. Indeed, making full use of the new technologies will rely on the IT skills of staff within organisations.

In January 1999 the Australian Government released its vision for Australia in the information age, and believes that industry will be uncompetitive without e-commerce (Alston 1999). A priority is to target barriers and to encourage the use of business-to-business (B2B) e-commerce. Technical barriers of bandwidth capacity and incompatible IT systems are currently under investigation. A majority of small and medium sized enterprises (SMEs) have Internet access in Europe and United Kingdom (70\%), and in the United States (80\%) (Hobley 2001). Intemet access does not, however, equate with e-business practices, but is the first step to being involved in e-business.

Being involved in e-business activities raises many issues particularly for SMEs. This new way of doing business requires staff with expertise in the new technologies, and SMEs will not necessarily have dedicated IT staff to enable them to gain the necessary competitive advantage in the global marketplace. While the advantages of e-commerce to large organisations can be justified, particularly if the organisation has specialised IT staff, SMEs may have difficulties firstly in meeting the initial costs and then the on-going expenses of maintaining the operation (Farmer 1996). Government programs focus on raising the awareness of SMEs to the trading opportunities offered by e-commerce, however SMEs are not conducting business on-line as quickly as larger companies (DFAT 1997).

SMEs constitute $94-96 \%$ of commercial organisations in Australia (ABS 1998) and therefore play a major role in the Australian economy, as well as contributing to private sector employment. ABS defines manufacturing SMEs as organisations with less than 200 employees, and annual turnover less than $\$ 20$ million. Small 
organisations will not take up new technologies unless they perceive an advantage to do so, or an immediate disadvantage in not taking them up (Clarke 1997).

Barriers to doing business on-line can be categorised as having a technical or a social perspective. Technical barriers include inadequacy of telecommunications infrastructure and security of transactions (Wai-Pun et al. 1997). Social barriers range from generally not trusting information technology (Crawford 1998); lack of knowledge about conducting business on-line and lack of IT skill of staff (Clarke 1996; Marzbani 1998; Crawford 1998); through to lack of awareness about possible uses of the Internet (Wai-Pun et al. 1997). Telstra (1998) conducted a survey of Australian SMEs and found that the major barrier was lack of personal contact between the organisation and the customer. The viewpoint that customers were not ready to do business on-line was also rated highly as a barrier. Interestingly only $5 \%$ of respondents felt security was a barrier to implementation. Further, the Australian Industry Group's (AIG) report highlighted reasons for not obtaining an Internet connection as cost of access, and lack of IT skill (AIG 1999). Barriers to European SMEs not becoming involved in using the Internet have been identified as lack of time (46\%), lack of information (31\%), and lack of training (30\%) (Hobley 2001).

The Australian Industry Group reported that $78 \%$ of its members had an Internet connection (AIG 1999). A study conducted in Tasmania revealed that $77 \%$ of respondents used computers, with $37 \%$ having an Internet connection, and 23\% a web page (Chau and Lawrence 1998). Further, 23\% of respondents to the Tasmanian study indicated plans for a web page within the next year. In Queensland, AIG found that $60.5 \%$ of members had an Internet connection (AIG 1998). US SMEs with Internet access is $80 \%$ (Hobley 2001 ), however, only $32 \%$ of American manufacturers had a web page (Caswell 2000). Considering that e-commerce is in its beginning phase, Australia is viewed as a world leader in e-commerce initiatives by the OECD, which rates Australia ahead of most of its 29 member countries. Australia is ranked third in the world (behind Finland and the US) in Internet use.

Current literature in the area has produced success stories for SMEs, but not usually within the manufacturing industry. An Internet presence for manufacturing organisations would see the geographical distances that historically have isolated Australia from global trade broken down.

This paper reports on a comparative research project that forms part of an integrated study of e-Business in Australia. The project will focus on similarities and difference between small and medium organisations in two manufacturing regions, ie South West (SW) Sydney and South East (SE) Melbourne. Previous studies in these regions will be used for comparative purposes (Lawson et al. 1999; Lawson et al. 2001). The regions were selected by industry associations as having significant manufacturing bases, and as being equivalent regions in manufacturing terms.

Specific aims of this project are to identify similarities and differences between small and medium organisations and between regions in terms of:

- business use of IT;

- $\quad$ specific and planned use of the Internet for electronic business;

- barriers to using the Internet for business;

- organisation's satisfaction with level of IT skills of staff; and

- current and planned staff training methods.

Models of the stages that an organisation moves through when embracing e-commerce have been developed (Cooper and Burgess 1998; Ho 1997; APT 1999). The Internet E-Commerce Staged Model (Cooper and Burgess 1998) will be used to evaluate the level of maturity of e-commerce for organisations in the study. This model was developed from existing models to reflect the modular adoption process for the manufacturing industry. The model was tested internationally to evaluate level of maturity of manufacturing organisations with a web presence. In 1998 most organisations began with an uncomplicated web page and added modules for functionality and complexity. This study will examine if manufacturing has progressed in their approach to web presence since 1998 .

\section{THE STUDY}

Manufacturing organisations located in SW Sydney and SE Melbourne regions that have an entry in the Australian Industry Group Yearbook (1999) comprised the population-sampling frame. One thousand one hundred and fifty one organisations (363 in SW Sydney and 788 in SE Melbourne) were identified as meeting the ABS (1998) definition for a manufacturing SME. Eight organisations were rejected from the SW Sydney study as their principal officer had participated in validating the survey. From the remaining group of 355 in SW Sydney, 178 organisations were selected. From the group of 788 in SE Melbourne, 394 organisations were selected. A total of 575 surveys were mailed to the principal officer (managing director, director, etc.) as set out in the AIG Yearbook. 
Overall 89 surveys were returned as left address or no longer in manufacturing (17 in SW Sydney and 72 in SE Melbourne). In SW Sydney 44 organisations completed the survey, representing $27.33 \%$ of the SW Sydney sample, and in SE Melbourne 126 organisations completed the survey, representing $39.13 \%$ of the SE Melbourne sample. The overall response rate was $34.97 \%$. The final page of the survey was a separate detachable page for the respondent to indicate their interest in the project by participating in an on-site interview. Eight case studies were undertaken in SW Sydney and six case studies in SE Melbourne.

The survey consists of four parts: (1) The organisation; (2) Use of computers and the Internet; (3) Planned use of the Internet; and, (4) Barriers to doing business on-line. Demographic data was collected from the respondent (age, gender, and position). A five point Likert scale was used for most questions, ranging from Very Important to Definitely Not Important, or Strongly Agree to Strongly Disagree. Space was provided for additional comments. From responses to the survey a profile of specific and planned use of the Internet for business was established, and related to the Internet E-commerce Staged Model (1998). Case study interviews examined experiences of the individual organisation in their specific and planned use of the Internet for business, and looked for explanations of the results of the survey, particularly barriers to involvement and staff expertise.

\section{Demographics}

Table 1 shows the manufacturing industry segments for each region as defined by the ABS (1998). Table 2 shows the samples broken down by small and medium sized enterprises. Figure 1 illustrates the regional samples by Industry Segment and Size of Organisation. Figure 2 shows the Internet Staged Model used to ascertain the organisations' level of maturity in using the Internet for business.

\begin{tabular}{lll}
\hline Segment * & \multicolumn{1}{c}{ SW Sydney } & SE Melbourne \\
\hline Metal product manufacturing & \multicolumn{1}{c}{$20(45.5 \%)$} & $25(19.8 \%)$ \\
Machinery \& equipment manufacturing & $9(20.5 \%)$ & $24(19.0 \%)$ \\
Textiles, clothing, footwear \& leather & $3(6.8 \%)$ & $12(9.5 \%)$ \\
Wood \& Paper product manufacturing & $1(2.3 \%)$ & $12(9.5 \%)$ \\
Food, beverage, tobacco & 0 & $8(6.3 \%)$ \\
Petroleum, coal, chemical & 0 & $8(6.3 \%)$ \\
Other manufacturing & $11(25.0 \%)$ & $37(29.4 \%)$ \\
*Segments as defined by ABS & $44(100.0 \%)$ & $126(100.0 \%)$ \\
\hline
\end{tabular}

Table 1: Manufacturing Industry Segments by region

\begin{tabular}{lll}
\hline Small/Medium * & SW Sydney & SE Melbourne \\
\hline Small: less than 20 employees & $22(50.0 \%)$ & $54(42.9 \%)$ \\
Medium: $20-200$ employees & $22(50.0 \%)$ & $72(57.1 \%)$ \\
* Size as defined by ABS & $44(100.0 \%)$ & $126(100.0 \%)$ \\
\hline
\end{tabular}

Table 2: Size of Organisation by region

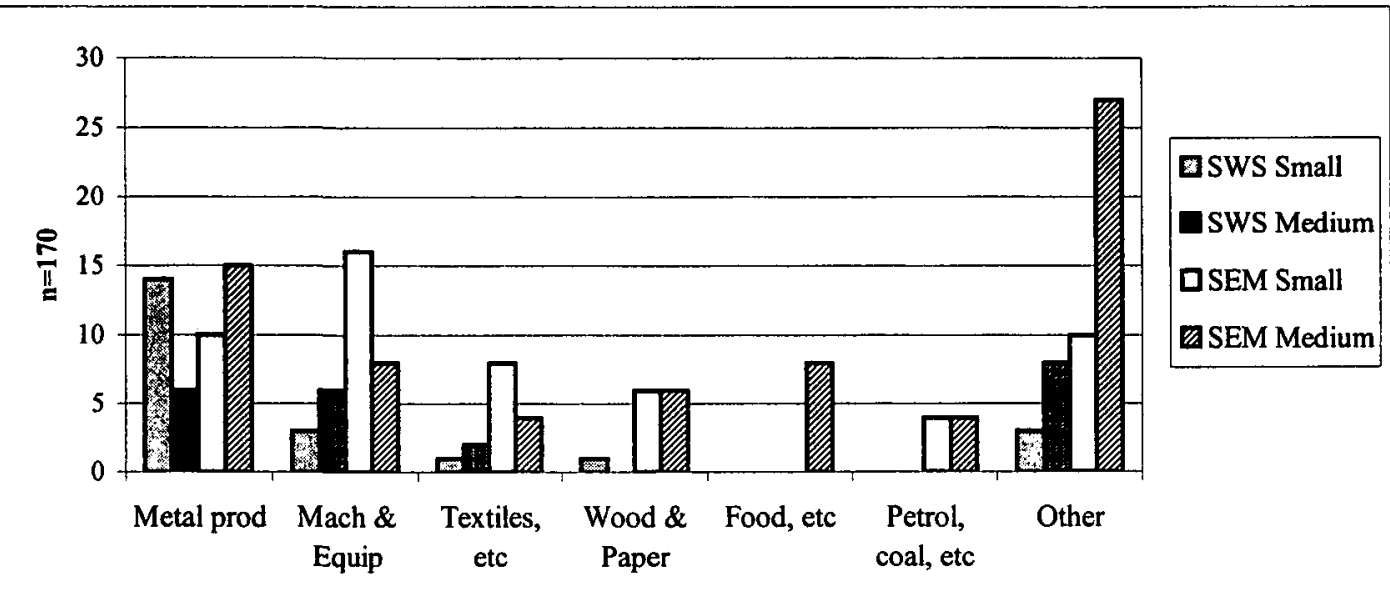

Figure 1: Regional Industry Segments by Small and Medium organisations 


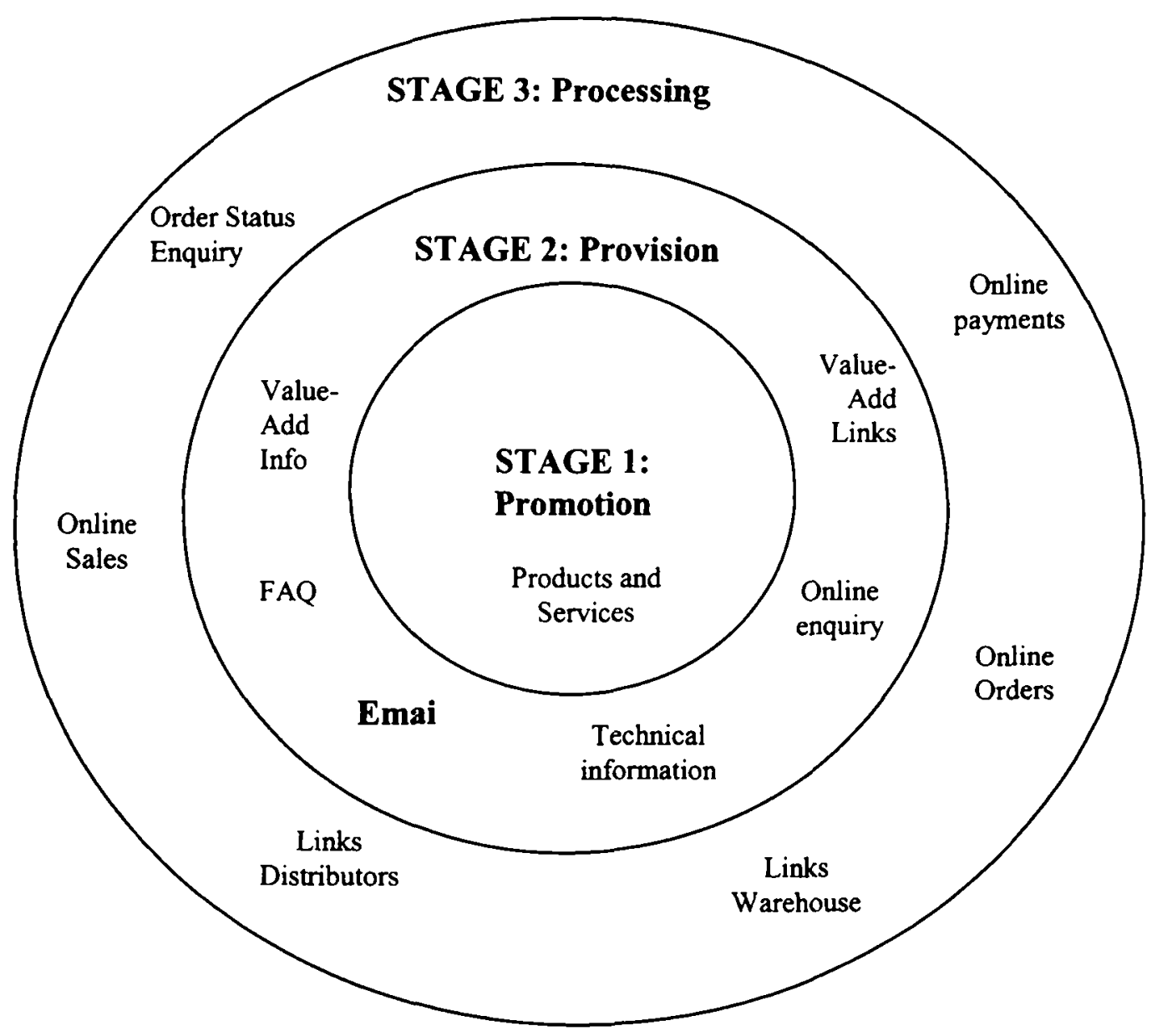

Figure 2: Internet Staged Model (Cooper and Burgess 1998)

\section{RESULTS}

Demographic data for the survey revealed the mean age of the sample was 44.8 years, with a total of 146 males and 22 females. Position of the respondent was divided into executive (managing directors, CEOs, etc) and nonexecutive (general managers). The executive group consisted of 74 males and 3 female (mean age 45.29 years), and non-executive group consisted of 72 males and 19 females (mean age 44.32 years). Based on t-test analysis, there were no significant differences in survey responses based on age, gender or position beld. Twelve males and two females participated in the case study interviews, with the mean age group of 40-49 years. Respondents generally agreed that the important issues facing the organisation were trying to make a profit $(89.9 \%)$ and staying ahead of the competition (87.1\%). Results of the study based on the aims of the project are set out below.

\section{Business use of Information Technology}

Respondents indicated that computers were essential for processing information for business (94.95\%). Table 3 shows the use of IT for business, overall and broken down by region. Five respondents indicated that the organisation did not use computers. Results are based on the remaining 165 respondents. All organisations used desktop applications to conduct their business, with all organisations using spreadsheets and $97.25 \%$ using word processing. One hundred and fifty one organisations $(88.8 \%)$ indicated that they had an Internet connection, with $81.8 \%$ utilising email communications, $41.2 \%$ had a web page, and $14.7 \%$ made some use of transaction processing via the Internet. 


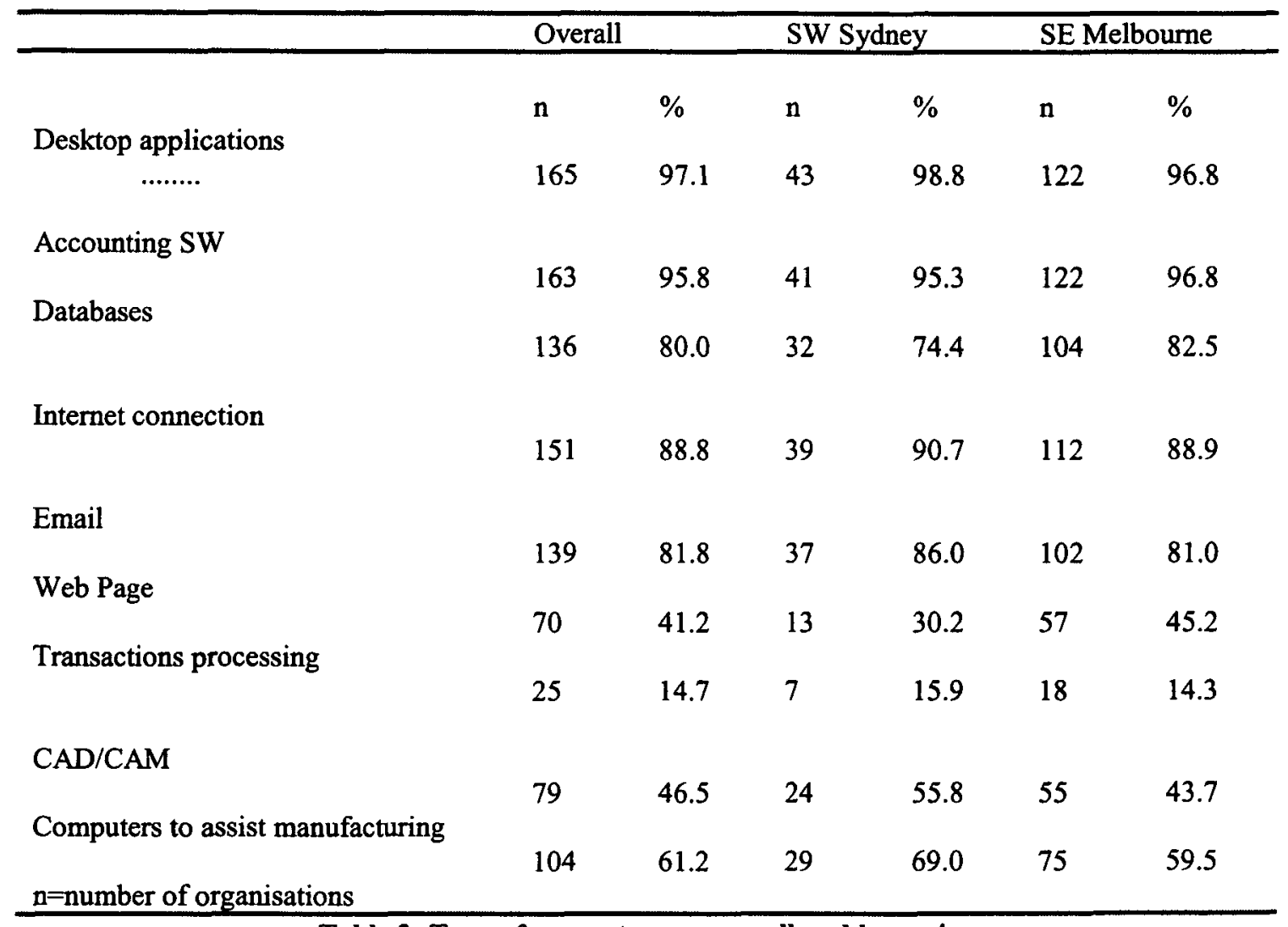

Table 3: Type of computer use overall and by region

Based on t-test analysis no significant differences were found between regions on business use of IT. However, some significant differences were found between small and medium organisations. Differences indicate that medium organisations use some technology more than small organisations, ie accounting software $(t=3.045$, $p<.01)$, databases $(t=2.987, p<.01)$, and computers to assist manufacturing $(t=3.998, p<.01)$. No significant differences were found with Internet connection, email, web page and transaction processing between small and medium organisations.

The extent that manufacturing SMEs are using IT for business in the both regions demonstrate an acceptance of computers, with some organisations moving to doing business on-line. From the organisations that took part in this study, a majority have indicated their plans to move to transaction processing via the Internet within five years. At present, the main use of the Internet for those with an Internet connection is email as a communication tool. 


\section{Actual and Planned use of the Internet}

Table 4a shows the stage that the organisations with a web page (13 in SW Sydney, 57 in SW Melbourne) have reached in their use of the Internet for business, and Table $4 \mathrm{~b}$ shows the stage that the all responding organisations planned to be within the next five years.

\begin{tabular}{|c|c|c|c|c|c|c|}
\hline & SW Sydney & & & SE Melbourne & & \\
\hline & $\mathbf{n}$ & $\%$ & & $\mathbf{n}$ & $\%$ & \\
\hline STAGE 1: Promotion & 2 & & 15.4 & 3 & & 2.3 \\
\hline STAGE 2: Provision & 4 & & 30.8 & 36 & & 28.6 \\
\hline STAGE 3: Processing & 7 & & 53.8 & 18 & & 14.3 \\
\hline * 13 orgs with web page in SW & $13 *$ & & 100. & $57 * *$ & & 100.0 \\
\hline $\begin{array}{l}\text { Sydney } \\
* * 57 \text { with web page in SE } \\
\text { Melbourne }\end{array}$ & & 0 & & & & \\
\hline
\end{tabular}

Table 4a: Actual Internet use related to the Internet Staged Model by regions

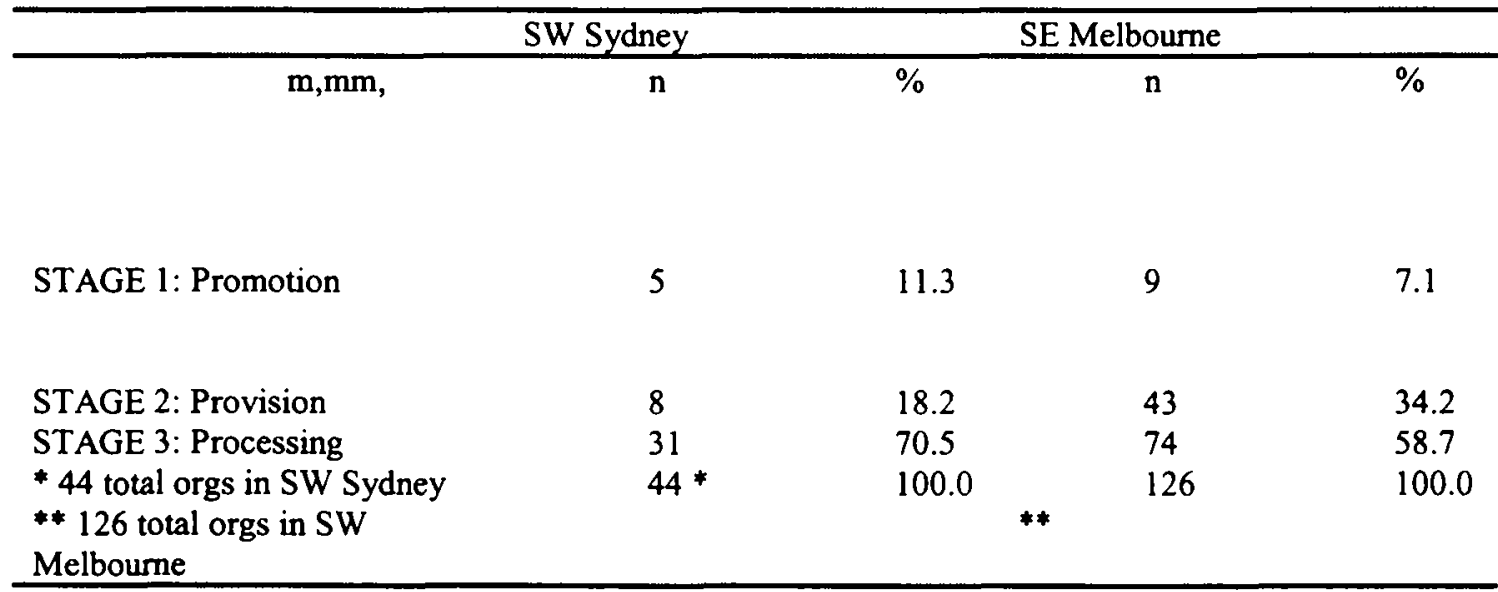

Table 4b: Planned Internet use related to the Internet Staged Model by regions

Based on t-test analysis no significant differences were found between regions or between small and medium organisations in relation to their actual or planned use of the Internet for business. Overall $41.0 \%$ of the organisations indicated that they had a Web Page, with $14.7 \%$ of respondents at Stage 3: Processing. However, a majority of the surveyed organisations $(90.8 \%$ ) planned to be at Stage 2 or Stage 3 within five years, with some positive attitudes towards moving in this direction:

"When dealing with larger companies, it will become essential. The majority of people will eventually shop/enquire on line (maybe 5-10 years), so business will have to move with technology. Long term, we expect that at least $50 \%$ of our business will have some exposure to an Internet site that we are on, either our own or one of our customers' sites." (Managing Director, male, 45 years, small organisation in Metal product manufacturing, SE Melbourne)

The assertion, that SMEs will not take up new technologies unless they perceive an advantage to do so, or an immediate disadvantage in not taking them up (Clarke 1997), is supported by the following comments:

"The whole 'net' thing is too abstract for most 'conventional' businesses to absorb. When it is finally put into a 'what it will do for you' format - without the YOU BEAUT extras, it will change." (Managing Director, male, 45 years, small organisation in Metal product manufacturing, SE Melbourne)

Case study organisations used their Internet connection to send email (both internal and external to the organisation), to do their banking, and to download files (eg drawings). All case study organisations were in 
various stages of planning and upgrading their web sites. Organisational web sites included Stage 1 with some elements of Stage 2, or Stage 2 with some elements of Stage 3 of the Internet Staged Model. Active planning was well under way for the next one to five years, with on-line ordering, and order status enquiry being viewed as important features for the evolution of the web site.

The trend in the survey towards Stage 3 is also reflected in discussions with the case study organisations. In SW Sydney, case study organisations raised the issue of needing to conduct parallel business processes, for their online customers, and for their customers who do not use technology. They also highlighted that the manufacturing industry has organisations (particularly small organisations) that do not use technology. In addition, it was indicated that B2B transactions in manufacturing were generally carried out in person or by phone. Moving to on-line transactions will involve a change in this traditional approach. As a group, the case study organisations identified benefits (wider marketing, better communication, improved business practices and increased business) and risks (cost of implementing and maintaining the web site, loss of knowledge of the transaction and possibly the product, and the web site not necessarily creating a positive image) associated with conducting business online (Lawson et al. 2001).

\section{Barriers to Internet use}

Based on the 170 organisations that responded to the survey in SW Sydney and SE Melbourne, Table 5 shows the top four (of 12 listed) barriers to the organisation becoming involved in e-commerce. Respondents were asked to indicate their agreement with statements by circling a number on the Likert scale ( $l=$ Strongly disagree to $5=$ Strongly agree). The four barriers shown returned a mean higher than 3 . SW Sydney had an additional barrier with a mean higher than 3 (ie, Not sure how many people are using the Internet, mean=3.14).

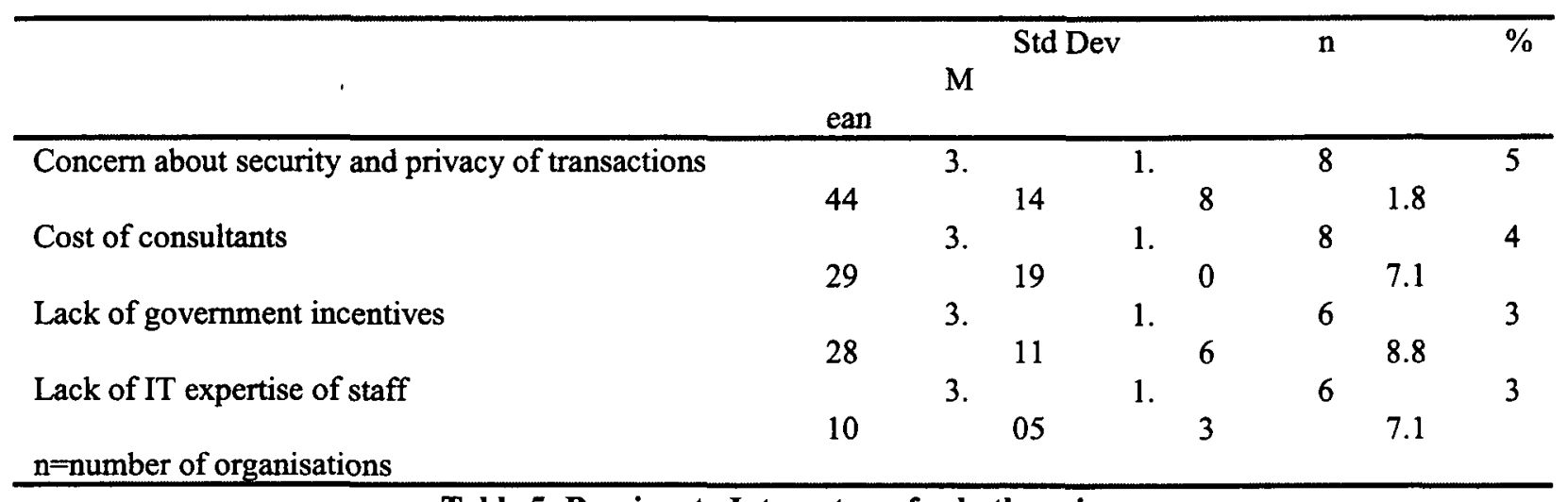

Table 5: Barriers to Internet use for both regions

T-test analysis revealed no significant differences between regions or between small and medium organisations on the top four barriers to becoming involved in doing business on-line.

However, two barriers listed at equal fifth position overall warrant further examination:

(a) Lack of cost effective telecommunications infrastructure (Overall Mean 2.95)

While no significant difference exists between regions, the difference between small and medium organisations was found to be significant:
Small organisations
Medium organisations
Mean 2.78
Mean 3.13

T-test analysis $(t=2.272, p<.05)$ indicates that medium organisations rate "lack of cost effective telecommunications infrastructure" as important to plans to becoming involved in doing business on-line.

(b) Not sure how many people are using the Internet (Overall Mean 2.95)

While no significant difference exists between regions, or between small and medium organisations based on t-test analysis, the mean for small organisations (3.06) indicates the these organisations believe that "not knowing how many people are using the Internet" is important to plans to becoming involved in doing business on-line.

Barriers that have slowed down the adoption of Internet as a viable way of doing business have similarities with other studies. In this study concern about security and privacy of transactions $(51.8 \%)$ is one of the main obstacles. Other studies have rated this barrier lower, and barriers such as inadequate speed of transmission, lack of knowledge about conducting business on-line, and lack of IT skill of staff, higher. The high level of concern about security may be a characteristic of the manufacturing industry, or the regions.

Cost of consultants was the second highest barrier (51.8\%). This finding is consistent with an overseas study (Hoffman et al. 1998), and was a feature of the discussions with case study organisations both in regions. Lack 
of government incentives was the third highest barrier, and while governments are moving on this issue, perhaps not in practical ways which are relevant to the manufacturing industry.

Case study organisations, while acknowledging that security and privacy of transactions was a barrier, believed that cost of consultants, integrating current systems, and lack of IT expertise within the organisation were barriers to be overcome in the evolution of conducting business on-line. Getting the right people to set up the web site which looks good, provides functionality and easy navigation, as well as ongoing support was viewed as critical to maintaining a quality assured standard, particularly when considering functions that would be provided at Stage 3.

Experiences of two organisations revealed that cost of consultants vary dramatically, with quotes appearing to offer the same service varying from $\$ 1,000$ to $\$ 10,000$. Interestingly, a consultant provided a quote for a web site with particular features at $\$ 40,000$, and when approached with the same specification the following year, quoted $\$ 6,000$. These inconsistencies have created an atmosphere of suspicion, with a number of comments, ie:

"Not easy to get good IT people who know what they are doing - consultants charge about \$120 per hour and are very expensive - quality of their work depends on how well YOU know computers." (Manager, male, 40-49 years, medium organisation in Other manufacturing. SE Melbourne).

"The area is so new, consultants are learning at their customers expense at very high fees - smoke and mirrors effect - IT is a very large field, hard to know it all." (Director, male, 30-39 years, small organisation in Other manufacturing, SE Melbourne).

All of the respondents to the survey in SW Sydney, and $70 \%$ of respondents in SE Melbourne believed that the manufacturing industry has not been made aware of what is available for the move to doing business on-line. No significant difference was found with this belief between regions or between small and medium sized organisations. This lack of awareness is definitely a barrier to an organisations becoming involved in ecommerce.

In SW Sydney, not understanding the process was also emphasised as a barrier that overlaps with the need to deal with consultants. The need to go out and research was identified as a problem, not knowing who to trust, and the lack of a central place for information related to doing business on-line for SMEs. The need to work differently was highlighted and to get training for staff was also viewed as a barrier. Currently, within some organisations there was none or very little expertise to maintain the web site, and very little time to allocate to training. In contrast, organisations in SE Melbourne already were in various stages of developing and enhancing their web sites, either by internal people (not necessarily designated IT staff), or were outsourcing the work. Ideas of what is available and possible were evident, with acknowledgement that the cost of consultants was a barrier. As a consequence, more confidence in dealing with consultants was apparent.

Lack of staff IT expertise had led to existing information technology not being used effectively, and a belief by some of the case study organisations that the situation will be exacerbated with the introduction of new web technologies. In SW Sydney, the issue of workload was raised by a number of the case study organisations, which were concerned about the need for parallel systems, and the need to deal with a higher volume of enquiries. Parallel systems would be necessary to enable the organisation to deal with additional or existing customers with on-line capabilities, and to provide for existing customers without technology. Strategies to deal with more enquiries were viewed as important in maintaining a quality assured standard. Case study organisations were generally satisfied with the current level of staff IT expertise for management and office staff categories, and were looking at recruitment practices to ensure new employees were computer literate in all categories.

\section{Level of staff IT skills and training}

One of the aims of the project is to determine level of satisfaction with IT skills of staff. The lack of IT expertise of staff was identified as one of the barriers to becoming involved in e-commerce. For this series of tables, respondents were asked to tick as many of the items as applicable to their organisation. Table 6a shows the organisation's satisfaction with the current level of IT skills by staff categories. Table 6b shows the top 5 (of 8 listed) IT training methods currently used for the various staff categories. Table $6 \mathrm{c}$ shows the top 5 (of 9 listed) IT training methods planned to meet the organisation's business strategies.

\begin{tabular}{llll}
\hline & $\mathbf{n}$ & & $\%$ \\
\hline Management (salaried employees) & & 111 & 65.3 \\
Office employees & 123 & & 72.4 \\
Factory (award employees) & 51 & 30.0 \\
n=number of organisations & & & \\
\hline
\end{tabular}

Table 6a: Organisation's satisfaction with level of staff IT skills by Staff Category 
T-test analysis revealed no significant difference between regions or between small and medium organisations based on satisfaction with the current levels of IT skills of staff at management, office and factory categories.

\begin{tabular}{lllllll}
\hline & \multicolumn{2}{l}{ Management } & Office & \multicolumn{3}{l}{ Factory } \\
\hline In-house training with internal people & $\mathrm{n}$ & $\%$ & $\mathrm{n}$ & $\%$ & $\mathrm{n}$ & $\%$ \\
& 109 & 64.1 & 112 & 65.9 & 70 & 41.2 \\
External training courses & & 58.8 & & 61.2 & & 32.4 \\
Trained to current level of recruitment & 100 & 54.7 & 104 & 54.1 & 55 & 36.5 \\
In-house training with external people & 93 & 51.8 & 92 & 55.9 & 62 & 31.2 \\
Computer based tutorials with product & 88 & 50.0 & 95 & 50.0 & 53 & 24.7 \\
n-number of organisations & 85 & & 85 & & 42 & \\
\hline
\end{tabular}

\section{Table 6b: Organisation's IT training methods used for Staff Category}

T-test analysis revealed no significant difference between regions on current training methods. However, some differences were revealed between small and medium sized organisations:

(a) Small organisations employ factory staff who are trained to their current level at recruitment more than medium organisations $(t=3.746, p<.01)$.

(b) Medium organisations send office staff to external courses more than small organisations $(t=2.239$, $\mathrm{p}<.05)$.

(c) Medium organisations use in-house training with internal people more than small organisations for their management and office staff categories $(t=2.750, p<.05)$.

(d) Medium organisations use in-house training with external people more than small organisations for their office and factory staff categories $(t=2.530, p<.05)$.

(e) Medium organisations employ permanent IT staff more than small organisations ( $\mathrm{t}=2.400, \mathrm{p}<.05)$.

(f)

\begin{tabular}{llll}
\hline & $\mathrm{n}$ & & $\%$ \\
\hline In-house training with internal people & & 113 & 66.5 \\
Employ people with appropriate knowledge & & 111 & 65.3 \\
Self-taught staff within organisation & 103 & & 60.6 \\
Knowledgeable employees & 99 & & 58.2 \\
Consultants & 95 & & 55.9 \\
n=number of organisations & & & \\
\hline
\end{tabular}

Table 6c: Organisation's IT training methods planned

T-test analysis revealed no significant difference between regions on planned training methods. However, small organisations used their knowledgeable employees more than medium organisations $(t=2.548, p<.05)$.

The level of IT skills of staff will affect decisions about moving to doing business on-line, particularly if the level of skill is low, or problems have been experienced in getting staff trained. In these circumstances, lack of IT expertise of staff is viewed as a barrier. Organisations rely on in-house training with internal people, and plan to continue this trend to meet the organisation's strategic plan for the next five years. Satisfaction with the level of IT skills of management $(65.3 \%)$ and office employees $(72.4 \%)$ is much higher than satisfaction with factory employees $(30.0 \%$ ). Organisations are now looking at employing staff with general computer literacy (not package specific) at the factory level:

"I expect computer literacy on recruitment, even from factory staff. There is not a guy here who doesn't touch a keyboard." (Managing Director, male, 40-49 years, small organisation in Textiles, etc., SE Melbourne)

Consistent with the survey, case study organisations facilitated in-house training by sending one member of staff to an external course who then passes on the knowledge to staff:

"Owner/Manager learnt system on external training course and then trained office staff" (Owner, female, 37 years, small organisation in Metal product manufacturing, SW Sydney) 
This approach was extended further by some case study organisations where introductory training (email, Internet) was handled by internal staff, with external courses for more advanced training (Office, MYOB, Photoshop).

However, the acknowledgment that new IT skills are necessary if the organisation is planning to move to doing business on-line is demonstrated by the ranking of "employing people with appropriate knowledge" close to "inhouse training with internal people". Case study organisations in SE Melbourne raised some interesting issues related to levels of IT expertise of existing staff that needed to be addressed, ie top management under-utilising the technology, inevitable staff turnover, reluctance of factory and older employees. The need to recruit staff with general, rather than package specific skills was also highlighted, as was the need to address the issue of file management (Lawson et al. 2001).

\section{DISCUSSION}

The results of the study found that while almost all organisations use computers, a majority have an Internet connection that they exclusively use for email, and only a small number of organisations are involved in transaction processing. Barriers are mostly non-technical, and planned IT training methods for staff includes employing people with appropriate knowledge to supplement current training methods. Medium organisations appear to be further along the diffusion process, with organisations planning the evolution of their web site and exploring issues related to content and design. While small organisations are planning to move to doing business on-line, their knowledge of the potential benefits offered by involvement in e-commerce is only superficial.

One way to overcome this lack of knowledge would be for industry associations to get closer to the problem, by disseminating information and conducting seminars in a format acceptable to SMEs, with special focus on small organisations. This may need a change of focus, as mentioned in this comment:

"Industry groups are focussed on government regulations rather than Industry tactics or direction of o/s competitors." (Manager, male, 39, medium organisation in Machinery and equipment manufacturing, SW Sydney)

The survey in both studies highlighted the need for manufacturing to be made aware of the benefits and risks of SMEs becoming involved in e-commerce. The case study interviews from both studies provided insight into the role that industry associations could provide, namely:

- A central information centre of electronic commerce resources specifically for SMEs: newsletters, booklets, where to find programs and seminars;

- Liaison with regional associations to provide: seminars, briefings at regional level relevant to manufacturing SMEs;

- Globally raising the profile of manufacturing in Australia.

Raising awareness that can lead to adoption of the new technologies is a priority of the Australian Government, however actually getting education to SMEs needs to be handled at a regional level to overcome barriers associated with doing business on-line. Regional associations could provide a one-stop point for information for e-business.

The process of diffusion identifies three groups that would need to be addressed: early adopters, those who are aware, and those who are not aware. Some subsidy from the industry association was suggested as a way of involving SMEs who are currently not aware of the new technologies. Certainly, without post-adoption support the early adopters group can plateau or move away from the new technologies. Industry associations have a role in the diffusion process for manufacturing, and more specifically to SMEs without IT personnel and expertise.

The studies revealed a need for a global business focus in manufacturing, and a need for regional networking and education on how to achieve on-line business. The following comment raises the need to support the early adopters, as well as those who have not yet conducted some form of business on-line:

"The early adopters have broken the ice, and others will come on board, so the next wave will be quite a big one." (Director, male, 30-39 years, small organisation in Other manufacturing, SE Melbourne)

Industry associations at national level could focus on providing a central point for resources for SMEs wishing to become involved in e-commerce, and liaise with regional associations to provide the face-to-face interaction at local level. Almost all case study organisations mentioned that they did receive a lot of paper from their national industry association, which was mostly not read. This distribution by mail is not meeting the needs of SMEs, and a more timely way of conveying information could be explored. Certainly, targeting early adopters, those who are aware, and those who are not aware, and providing these groups with relevant information would be a step in the right direction.

Modification to the Internet Stage Model (Cooper and Burgess 1998) is recommended for manufacturing SMEs in Australia based on survey results and case study interviews. As organisations have progressed in their approach since the introduction of the model and are planning for interactivity on their web site as an initial step, 
the barrier between Stage 1 and 2 should appear as a soft barrier indicated by a broken circle. The barrier between Stage 2 and 3 should be strengthened to a hard barrier, as organisations believed that their business practices and other issues needed to be addressed before crossing this barrier. In contrast, having a web presence that encompassed Stage 1 and elements of Stage 2 could be accomplished alongside existing business practices.

The choice of SW Sydney and SE Melbourne by industry associations based on the regions being equivalent in manufacturing terms, is supported by the findings that no significant differences were found between the regions on their business use of IT, actual and planned use of the Internet for business, barriers to adoption, and staff IT expertise and training issues.

Significant differences were found between small and medium organisations on business use of some software applications, and current IT training methods. Medium organisations use some current IT training methods and employ permanent IT staff more than small organisations. Small organisations could be targetted by government, industry associations and the education sector. The barrier of "lack of cost effective telecommunications infrastructure" had a mean of 3.13 for medium organisations. This is a current target for the Australian government. The barrier of "not sure how many people are using the Internet" had a mean of 3.06 for small organisations. Industry associations could acknowledge that small organisations need a particular focus.

\section{CONCLUSION}

While e-business means conducting business on-line using paperless methods, it needs a multi-disciplinary approach to the diffusion process. The technology is available, and adoption will rely on how well the diffusion process is handled by government and industry associations.

This research has highlighted four integrated areas in the diffusion process:

- What government and industry association can do: provide information to raise awareness adapted to manufacturing SMEs

- What education sector can do: provide knowledge and skills in electronic commerce for graduates

- What SMEs can do: (not just IT-related courses)

participate in the diffusion process by liaison with industry associations develop strategies for dealing with consultants identify and develop strategies about workload issues

- What Consultants can do: interact with SMEs to provide quality service

As the diffusion process evolves in the future, the main issue in electronic business will move away from the technology, to a functional and service level. For SMEs, business will be carried out by staff with support from consultants. Issues will continue to be IT expertise of staff and quality of consultants. The next stage of this research involves exploring what industry associations are offering, and planning to offer SMEs; and what incentives are being offered by the Australian government to encourage participation of SMEs in moving towards conducting business on-line.

The use of the Internet by manufacturing SMEs in regional Australia (41.2\% with a web page) is more than comparable with the national average of $23 \%$, and with US manufacturers at $32 \%$. Manufacturing industry associations will have a role to play in supporting SMEs in developing strategies for doing business on-line. The evolution of the diffusion process will rely on awareness and education. This will be the key to moving towards achieving the Australian government's goal of making industry competitive in the global marketplace

\section{REFERENCES}

Alston, R. (1999) Australia's e-commerce report card [on-line]. Department of Communications, Information Technology and the Arts. Available from:- $h$ ttp://www.dcita.gov.au/cgi-bin/graphics.pl?path=3789 [Accessed 3 July 2000].

APT Strategies. (1999) Strategic Internet Business Study, [on-line]. Available from:http://www.aptstrategies.com.au/review/researchmethod.htm [Accessed 3 July 2000].

Australian Bureau of Statistics. (1998) Characteristics of small business,[on-line]. Available from:http://www.abs.gov.au/Ausstats/ [Accessed 3 July 2000].

Australian Industry Group. (1999) Yearbook. Sydney: Australian Industry Group.

Australian Industry Group. (1999) Australian Survey by Regions. Sydney : Australian Industry Group.

Australian Industry Group. (1998) Queensland Members' Survey: Information Technology/E-Commerce Survey. Brisbane : Australian Industry Group. 
Caswell, S. (2000) US Manufacturers not B2B e-commerce ready. E-Commerce Times, [on-line]. Available from:- http://www.ecommercetimes.com/news/articles2000/000223-6.shtml [Accessed 3 July 2000].

Chau, S., and Lawrence, K. (1998) Electronic commerce knowledge, capabilities and utilisation: the Tasmanian perspective. In: CollECTeR'98 Conference Proceedings, September 1998, [on-line]. Available from: http://www.collecter.org/Coll98.proc.html [Accessed 3 July 2000].

Clarke, R. (1997) What's Holding Up EC in Australia?, [on-line]. Available from:http://www.anu.edu.au/people/Roger.Clarke/EC/Impeds97.html [Accessed 3 July 2000].

Clarke, R. (1996) Towards a theoretical framework for collaborative electronic commerce projects involving small and medium-sized enterprises. In: Conference Proceedings for $9^{\text {th }}$ International Conference, EDIIOS, Bled, Slovenia, 10-12 June 1996, [on-line]. Available from:http://www.anu.edu.au/people/Roger.Clarke/EC/CamCla960612.html [Accessed 3 July 2000].

Cooper, J., and Burgess, L. (1998) The status of Internet Commerce in the manufacturing industry in Australia: a survey of metal fabrication industries. In: CollECTeR ' 98 Conference Proceedings, September 1998, Sydney, Australia [on-line]. Available from:- $h$ ttp://www.collecter.org/Coll98/ [Accessed 3 July 2000].

Crawford, J. (1998) Networked enterprise web strategy: a project to get smaller enterprises on-line. Department of Industry, Science and Tourism, [on-line]. Available from:http://www.dist.gov.au/infoind/busonline/gbo.pdf [Accessed 3 July 2000].

Department of Foreign Affairs and Trade. (1997) Putting Australia on the New Silk Road. Canberra : National Capital Printing.

Farmer, C. (1996) Nothing but net. Success, 43, 3, 58.

Forester, T. (1985) The Information Technology Revolution. Oxford : Blackwell.

Ho, J. (1997) Evaluating the WWW: a global study of commercial sites. Journal of Computer-Mediated Communication, 3, 1, (June), [on-line]. Available from:- http://www.ascusc.org/jcmc/vol $3 /$ issuel $/ \mathrm{ho}, \mathrm{html}$ [Accessed 3 July 2000].

Hobley, C. (2001) Just Numbers: Numbers on Internet use, electronic commerce, IT and related figures for the European Community, January 2001. European Commission's Electronic Commerce Team (Information Society Directorate General [on-line]. Available from http://www.drecommerce.com/justnumbers/ [Accessed 28 April 2001]

Hoffman, D., Novak, T. and P Chatterjee (1998). Commercial scenarios for the web: opportunities and challenges. Journal of Computer Mediated Communication 1, 3, [on-line]. Available from:http://www.ascusc.org/jcmc/voll/issue3/hoffman.html [3 July 2000].

Lawson, R., Cooper, J., and C. Alcock. (1999) Business On-line: manufacturing small and medium enterprises in south west Sydney. In: CollECTeR '99 Conference Proceedings, December, 1999, Wellington, New Zealand [on-line]. Available from:- http://www.collecter.org/Coll99/ [Accessed 3 July 2000].

Lawson, R., Alcock, C. and J. Cooper (2001) E-business adoption by manufacturing SMEs in regional Australia. In: Conference Proceedings for $14^{\text {th }}$ Bled Electronic Commerce Conference, June, 2001, Bled, Slovenia.

Marzbani, R., Wong, C., Holmes, M., Chick, H., Ghassemi, K. and P. Moore. (1998) stats.electronic commerce in Australia. Department of Industry, Science and Tourism, [on-line], April 1998. Available from:http://www.isr.gov.au/infoind/stats/ecomstat.pdf, [Accessed 3 July 2000].

Telstra Corporation Ltd. (1998) Survey of electronic commerce in Australian small and medium business, [on-line]. Available from: http://www.pacificaccess.com.au/sbi/, [Accessed 3 July 2000].

Wai-Pun, M., Farhoomand, A., and V. Tuunainen. (1997) A preliminary investigation of business opportunities on the Internet in Asia Pacific. In: Proceedings of the $1^{\text {si }}$ Pacific-Asia Workshop on Electronic Commerce, 5 April 1997, Brisbane : Queensland University of Technology. 